Abstracta Iranica

Revue bibliographique pour le domaine irano-aryen

Volume 32-33 | 2013

Comptes rendus des publications de 2009-2010

\title{
Almut Hintze. Treasures in Heaven. A Theme in Comparative Religion
}

\section{Mihaela Timus}

\section{(2) OpenEdition}

1 Journals

Édition électronique

URL : http://journals.openedition.org/abstractairanica/40118

DOI : 10.4000/abstractairanica.40118

ISSN : 1961-960X

\section{Éditeur :}

CNRS (UMR 7528 Mondes iraniens et indiens), Éditions de l'IFRI

\section{Édition imprimée}

Date de publication : 1 décembre 2013

ISSN : 0240-8910

\section{Référence électronique}

Mihaela Timus, "Almut Hintze. Treasures in Heaven. A Theme in Comparative Religion ", Abstracta Iranica [En ligne], Volume 32-33 | 2013, document 13, mis en ligne le 01 juillet 2016, consulté le 26 septembre 2020. URL : http://journals.openedition.org/abstractairanica/40118 ; DOI : https://doi.org/10.4000/ abstractairanica.40118

Ce document a été généré automatiquement le 26 septembre 2020.

Tous droits réservés 


\title{
Almut Hintze. Treasures in Heaven. A Theme in Comparative Religion
}

\author{
Mihaela Timus
}

\section{RÉFÉRENCE}

"Treasures in Heaven. A Theme in Comparative Religion », in : Shaul Shaked, Amnon Netzer, eds., Studies Relating to Jewish Contacts with Persian Culture throughout the Ages. Irano-Judaica. Jerusalem, 2008, p. 9-36.

1 L'étude tente d'identifier les expressions mazdéennes équivalentes à celle de «trésor dans le ciel» (Judaïsme, Christianisme). L'A. dresse une carte assez large des expressions, tant avestiques que pehlevies, qui remontent pour la plupart à l'idée de dépôt symbolique, pris en charge par ohrmazd. A titre d'exemple: 1. L'emploi de verbes tels "surveiller», "garder» (Y. 49.10, 28.10.) ou de formules impératives: «prends!", «fais le dépôt ! » (Y. 49.10.3). 2. L'emploi de deux catégories d'expressions avestiques et/ou pehlevies relatives à la notion de "dépôt»: a. physique, où la métaphore est empruntée au registre de la vie quotidienne, à savoir le dépôt de céréales (hambār) ou la trésorerie (ganj, ganjwar) ; b. mental, i.e. la mémoire, Ohrmazd étant nommé le gardien de la triade rituelle, celui « qui se rappelle les mérites » (av. hāta.marāni-, Y. 32.6).

2 Dans le sillage de R. Roth (1883) et de G. Klingenschmitt (1972), l'A. reprend la question de l'imaginaire de la balance qu'elle identifie dans certains passages (Y.33.1 ou bien Vd.

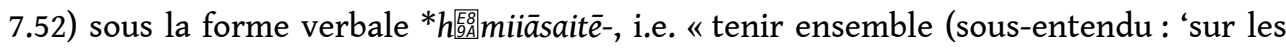
deux plateaux dans la balance') ", « être balancés d'une manière équitable ».

3 La comparaison avec des contextes vétérotestamentaires met en avant la particularité de l'expression mazdéenne eschatologique: l'idée de mémoire écrite est totalement absente. 


\section{AUTEURS}

\section{MIHAELA TIMUS}

Institut d'Histoire des Religions, Bucarest 